\title{
El Protocolo como ciencia propia en el ecosistema de la Comunicación. Espacios posibles para transformar una técnica en una disciplina científica
}

\author{
Fernando RAmOS FERNÁNDEZ \\ Universidad de Vigo \\ ferramos@telefonica.net
}

Recibido: $29 / 02 / 2013$

Aceptado: 25/06/2013

\section{Resumen}

La nueva ubicación del Protocolo como carrera universitaria, con todos los niveles previstos, obliga a un replanteamiento de su consideración como mera técnica formal al servicio de la imagen y la representación simbólica de las instituciones y los organismos, a través de los actos públicos. Su inclusión entre las carreras tradicionales de la Comunicación, de mayor abolengo y trayectoria, requiere dotarla de líneas de investigación rigurosas que supere la mera casuística meramente descriptiva de ceremonias y ritos, para profundizar en el estudio social, jurídico e histórico de los elementos que la conforman. Al convertirse en una carrera específica debe desarrollar, para serlo, su propio ámbito científico.

Palabras clave: Ceremonial, simbolismo, Ciencia formal, representación pública, imagen institucional

The protocol as science itself in the ecosystem of Communication. Spaces potential to transform a technique in a scientific discipline

\begin{abstract}
The new location of the Protocol and college career, with all the expected levels, requires a rethinking of consideration as mere formal technique to serve the image and the symbolic representation of institutions and organizations, through public events. Their inclusion among the traditional careers of Communication, ancestry and career high, giving it requires rigorous research lines that exceeds the mere casuistry merely descriptive of ceremonies and rites, to deepen the social study of the legal and historical elements that form. By becoming a specific career should develop to be, their own science.
\end{abstract}

Keywords: Ceremonial, symbolism, formal Science, public performance, corporate image

\section{Referencia normalizada}

RAMOS FERNÁNDEZ, Fernando (2013): "El Protocolo como ciencia propia en el ecosistema de la Comunicación. Espacios posibles para transformar una técnica en una disciplina científica". Estudios sobre el Mensaje Periodístico. Vol. 19, Núm. 2 (julio-diciembre), págs.: 1075-1089. Madrid, Servicio de Publicaciones de la Universidad Complutense.

Sumario: 1. Introducción. 2. Metodología y fuentes; 2.1. Formulación de la hipótesis. 3. El protocolo como norma jurídica. 4. Protocolo y valor histórico; 4.1. La estructura del Protocolo Oficial en España; 4.2. La adecuación del Protocolo a la realidad nacional; 4.3. El Protocolo como materia de estudio. 5. Conclusiones. 6. Referencias.

\section{Introducción}

La aprobación por parte de la ANECA de la nueva carrera de Protocolo y Organización de Eventos el 30 de septiembre de 2010 -en que nacen oficialmente estos estudios dentro de la familia de las Ciencias de la Comunicación- ha provocado una inacabable controversia en la comunidad científica, ya consolidada, acerca de no sólo 
de si esta titulación era necesaria ${ }^{1}$, más allá, de si el "Protocolo" puede ser considerado en algún momento una verdadera ciencia, o más bien una mera técnica dentro de la organización y la representación simbólica en actos y ceremonias al servicio de la imagen de las instituciones.

La mera observación del mercado de estudios reglados, cursos, estudios de post grado y toda variedad de entidades, academias y centros privados permite colegir la existencia de una oferta excesiva, no siempre de calidad, de modo que parece haberse extendido una suerte de moda en torno al protocolo, que hasta ahora venía siendo una materia (a veces meramente optativa), un itinerario en la carrera de Publicidad y Relaciones Públicas; o bien se desarrollaba a través de cursos de especialista universitario o master (por lo general títulos propios) en la Universidad pública, en tanto los centros privados ofrecían sus propios títulos de gran diversidad y contenido.

De manera más rigurosa, los estudios del Protocolo como materia de comunicación, vinculados a la Universidad se inician en la Universidad de Oviedo ${ }^{2}$, mediante títulos propios, al tiempo que es en la de Sevilla, donde la Doctora María Teresa Otero Alvarado (2000: 19) presenta la que puede ser considerada primera tesis con el rigor y la calidad de una verdadera investigación sistematizada, si bien su contenido se apoya en un desarrollo histórico a través de otras ciencias, especialmente la historia. Desde entonces, ya son muchos los investigadores que se han adentrado por este camino con variada suerte, pero siempre con notable afán de dar a sus trabajos la máxima calidad.

Planteada la cuestión, cabe preguntarse si realmente estamos ante una Ciencia como lo entienden Bruner (1965: 12) y Gambara (1995: 23) o precisan León, O. G., y Montero, I. (1997: 6 y ss). Y se podría añadir si, per se, al margen de los objetivos a los que sirve, es materia con entidad suficiente para el trabajo científico, como lo definen Alcira Franch (1994:21), Sierra Bravo (1993: 73) o Mercado (2009: 21). Y por supuesto, como lo estipula Eco (1982: 47).

Señala Carreras (1994: 17), que la característica fundamental del término "Ciencia” es su ambigüedad. Lo científico se entiende, en cada ocasión, según la conveniencia de quien lo define. De modo que corremos el riesgo de considerar como

1 La mera lectura de las salidas profesionales que ofrecen las dos universidades donde, de momento, se ofrecen estos estudios, la privada Camilo José Cela, y la pública Miguel Hernández, producen una inevitable sorpresa, al constar que, pese a contradecir las recomendaciones y desarrollo del Plan Bolonia -y el sentido común- ofrecen repetidamente ámbitos ya cubiertos por los estudios de Periodismo y Publicidad y Relaciones Públicas como es fácil constatar.

2 Anteriormente a esta iniciativa, gozaban de gran prestigio los Cursos de la Escuela Diplomática. Paralelamente, en el ámbito privado, apareció con gran éxito la Escuela Internacional de Protocolo, que actualmente compite con otros desarrollos parecidos, que han buscado el apoyo de universidades privadas y centros extranjeros, donde se ofrecen diversos estudios, desde grados a otras fórmulas que, a través de discutibles pasarelas y convalidaciones, permiten eludir con facilidad las normas que rigen el acceso a un grado oficial en la Universidad pública. 
científico algo que no lo es. $\mathrm{O}$ al contrario. ¿Es el protocolo una ciencia como tal? Si tomamos con referencia el mercado bibliográfico, nos asalta la primera duda: existe una interminable serie de monografías al respecto que, o bien tienen un carácter de manual práctico, descriptivo de la casuística más variada, pero que no siempre profundiza en el porqué de sus afirmaciones; o bien se trata de trabajos históricos, donde el relato de episodios del pasado, situaciones anecdóticas o sucesos variados extrae consecuencias sociológicas o políticas que sí elevan el rango de la publicación.

El positivismo del siglo XIX dotó de soporte ideológico a las Ciencias experimentales, al tiempo que reducía el ámbito del conocimiento a los aspectos sensibles de la realidad (Carreras Panchón, 1994: 17). De tal suerte, que se restringía el sentido de los científico a las disciplinas ocupadas en el estudio de la naturaleza (Biología, Física, Química, etc.). Pero era evidente que era una reducción simplista del conocimiento. Pronto habrían de irrumpir con fuerza y dinámica propias las Ciencias Sociales.

Llegamos pues a la definición moderna de Ciencia, en el sentido de "todo conocimiento de la realidad en sus causas, y dotado de un instrumento específico, el método, que le permite alcanzar sus fines" (Carreras, 1994: 19). Podríamos argumentar, en este caso, que el "Protocolo" no tiene fines propios, sino que es un instrumento para mejorar la presentación en público de las instituciones o, si se prefiere, visualizar el poder, la jerarquía y el rango de los personajes y las instituciones públicas. Por lo tanto, no pasaría de ser una técnica, pero sin los requisitos para ser considerado propiamente una ciencia. Pero quienes defienden su vigencia como conocimiento específico replican que lo mismo ocurre con las Relaciones Públicas, la Publicidad o el Periodismo, que carecen de objeto propio por sí mismos, sino que son artes al servicio de otros fines: mejorar la imagen y establecer contactos positivos a favor de las organizaciones, promover la venta o demanda de productos o servicios, o facilitar la formación de la opinión pública. No es menos cierto que incluso las ciencias más puras son ciencias de la utilidad; es decir, son aplicables a objetos distintos del conocimiento mismo. Dicho de otro modo, sirve para algo a la sociedad.

Por lo tanto, hemos de fijarnos si, por sus propios contenidos, el protocolo permite desarrollar una teoría científica a partir de los postulados ordinarios del trabajo intelectual. Este paso nos lleva a situarlo dentro de otra concepción de la Ciencia como recopilación de técnicas y métodos que nos permiten organizar de forma objetiva y accesible un conjunto de información, que puede ser adquirida a través de la experiencia o de la deducción.

\section{Metodología y Fuentes}

Entendemos que una Ciencia es básica, cuando se dedica simplemente a observar e interpretar la información que genera por este método y no formula ninguna teoría aplicable más allá de su propio espacio; es decir, no decanta reglas de posible aplicación universal, exportable a otros campos. La Ciencia aplicada transforma y enriquece los conocimientos científicos obtenidos a través de la Ciencia básica, y los aplica para resolver necesidades humanas. Es decir, en este caso sí es aplicable a otros ámbitos. Si estos conocimientos son certeros y son estructurados, pueden llegar a convertirse en leyes universales. 
Pero no siempre este esquema, propio de las Ciencias técnicas, es trasladable al territorio de las Ciencias sociales. La Ciencia avanza solamente a través de la investigación ordenada, ya que permite una reconstrucción conceptual de la realidad, que es cada vez más amplia, profunda y exacta. Aborda problemas circunscriptos, uno a uno, y trata de descomponerlos, de entender sus componentes; intenta descubrir los elementos que componen cada totalidad, y las interconexiones que explican su integración.

Es evidente que para analizar científicamente y explicarse qué es el protocolo y para formular una teoría sobre su conocimiento es imprescindible dotarse de otros recursos que la mera revisión de la amplísima bibliografía descriptiva (manuales, prontuarios, legislación, libros de estilo, tratados de etiqueta y ceremonial que hallamos en el mercado de las ideas).

La Historia, el Derecho (y en especial alguna de sus ramas o especialidades, desde el Derecho Diplomático al Derecho Premial), la Heráldica, la Vexicología, la Sociología, la Etnografía, la Retórica, la Literatura, la Proxemia, el Paralenguaje, la Kinesia y hasta la Mitología, entre otros, serán conocimientos que es preciso explorar para estructurar el armazón del conocimiento científico del Protocolo.

Hemos de ubicar necesariamente el protocolo en el territorio de las llamadas "Ciencias Formales" que, como su nombre lo indica, estudian las formas. Y nuestros hechos son los acontecimientos sociales de cierto rango, no los hechos naturales; pero que están sometidos a unas determinadas reglas, usos y tradiciones formales, expresados a través de la etiqueta y el ceremonial, muchas veces sustentado en la tradición y en los usos sociales consolidados.

Como nos enseña Bruner (1965: 24 y ss.) el enfoque científico puede describirse en términos de cierto número de características. Los científicos fundan sus descubrimientos en observaciones empíricas, las pruebas están arraigadas en la realidad objetiva y se compitan a través de los sentidos humanos o por sus extensiones. El enfoque científico pretende ser general e intenta establecer explicaciones conceptuales o teorías referentes a las relaciones entre fenómenos. Las metas más corrientes de la investigación son descripción, exploración, explicación, predicción y control de los fenómenos. También es posible describir la investigación en términos de la utilidad práctica directa que aspira lograr.

El Protocolo es una ciencia de resultados, que se expresa, de manera muy diversa, según las distintas culturas, pero que coinciden en el concepto de la "intuición de lo correcto"; es decir, del comportamiento humano adecuado y tempestivo en determinados actos y acontecimientos de la vida social, especialmente de aquellos que tienen un carácter simbólico, ritual o conmemorativo.

No deja de ser curioso que el más clásico de los manuales de Protocolo de la España reciente, conocido popularmente como el "El Urquiza", (Urquiza, 1932) dedicado al gran parte al ceremonial y el protocolo de la Casa Real española, fuese publicado en 1932; es decir, el plena II República. El libro está dividido en tres partes. En la primera explica que es la Diplomacia, para analizar ceremonial y el rango entre los Estados; las funciones del Cuerpo diplomático, su ceremonial, el modo de organizar los banquetes, las ceremonias palatinas y las condecoraciones. En la segunda 
se adentra en la simbología de himnos y banderas y la Heráldica, y concluye con un recorrido por los usos protocolarios de veinticinco países. Pero en realidad se centra en las grandes ceremonias de Estado que en lo que podríamos hoy denominar el protocolo moderno.

La vigésimo primera edición del Diccionario de la Real Academia de la Lengua española dice de la voz Protocolo:

(Del b. lat. protocollum, y este del gr. $\pi \rho \omega \tau o ́ \kappa o \lambda \lambda o v)$.

1. $\mathrm{m}$. Serie ordenada de escrituras matrices y otros documentos que un notario o escribano autoriza y custodia con ciertas formalidades.

2. m. Acta o cuaderno de actas relativas a un acuerdo, conferencia o congreso diplomático.

3. m. Regla ceremonial diplomática o palatina establecida por decreto o por costumbre.

4. m. Plan escrito y detallado de un experimento científico, un ensayo clínico o una actuación médica.

Pierre de Fouquières en el prólogo del célebre tratado de Protocolo francés de Serres (1982: 7), señala que las reglas y costumbres que han contribuido a que Francia sea reconocida por sus modales y su elegancia deben servir de ejemplo a todos aquellos que quieran desarrollar con dignidad y eficacia sus funciones [públicas], en tanto Berisso (2008: 29), apunta que es en Egipto, a partir del periodo neolítico donde va aparecer el ceremonial religioso y real, como necesidad social y norma de comportamiento, basado en los órdenes jerárquicos. Sgrselli (2006: 41), indica que la expresión "protocolo" expresa siempre un orden y una fórmula honorífica que debe ser respetada.

En nuestro tiempo, el estudio o la revisión de las fuentes del Protocolo nos lleva esencialmente en dos direcciones: La formulación jurídica del protocolo oficial, que los estados expresan a través de leyes y/o reglamentos específicos, por una parte por parte de las autoridades públicas, desde el Estado a los municipios, y los manuales de identidad corporativa, libros de estilo o normas de protocolo corporativo, del que se dotan las grandes empresas e instituciones privadas.

Delimitado el terreno de estudio, en el Caso de España, el repertorio legal es amplísimo: desde el Real Decreto 2009/83, de 4 de agosto, de Precedencias del Estado, a las disposiciones autonómicas y los reglamentos de las corporaciones locales y los cabildos, el Parlamento o el Poder Judicial, sin olvidar las Ordenanzas Militares, las disposiciones sobre honores, los símbolos nacionales y los tratamientos de la Familia Real, entre otros. En el espacio privado, corporaciones, fundaciones, empresas, asociaciones, clubes y entidades diversas fijan sus propias normas de protocolo y ceremonial para sus actos solemnes. La síntesis de este otro protocolo queda resumida en la definición de Urbina (1994: 29): "Protocolo es aquella disciplina que con realismo, técnica y arte determina las estructuras o formas bajo las que se realiza una acción humana importante". Lo cual viene esencialmente a coincidir con la acotación de María Moliner, cuando precisa que son el conjunto de reglas de cortesía y urbanidad usadas en cualquier sitio. En esa misma línea Fernández Campo lo definía como "la cortesía reglamentada" (Vilarrubias, 2000: 15-17). 
Nos movemos en el territorio de las Ciencias Sociales, donde hemos de buscar, esencialmente, la utilidad práctica de nuestro trabajo, Y hemos de combinar, por tanto, según el caso, los métodos deductivo e inductivo, poniendo en cada circunstancia el énfasis necesario. Partimos de las experiencias que nos brinda la propia observación de los fenómenos donde se despliega la ciencia o técnica del Protocolo, para enriquecernos con la investigación documental, el estudio de casos y la bibliografía especializada a la que recurrir en todo momento.

\subsection{Formulación de la hipótesis}

Para formular una teoría general del Protocolo es preciso superar la manida concepción que lo sitúa como una regla de comportamiento humano vinculada al ceremonial y a la etiqueta de determinadas ceremonias palatinas y oficiales. Hemos de entenderlo, por extensión, como el modo correcto de llevar a cabo y ejecutar una acción humana con éxito dentro de sus propios objetivos. De este modo hablamos del protocolo de los quirófanos, del protocolo de la emergencia en un submarino nuclear, etc. Pero ciñéndonos al espacio de la Comunicación institucional y corporativa, que es donde se sitúa el nuevo Grado de Protocolo, hemos de entender dos cosas:

a) Sentido estricto: Ordenación por rango de las autoridades públicas en un acto oficial. Es la visualización del Poder político, conforme establece la Constitución.

b) Sentido general: Técnica para organizar y desarrollar actos de carácter público al servicio de los objetivos de visibilidad, imagen pública, reputación y, en su caso, responsabilidad social y relaciones con sus entornos, de entidades privadas, empresas y corporaciones.

Como subraya Rodríguez Ennes ${ }^{3}$, a lo largo del devenir histórico, la prioridad jerárquica, leit motiv del protocolo, se ha erigido en un proceloso campo de disputas:

Con mayor o menor énfasis - pero sin excepción- desde los remotos tiempos faraónicos, hasta la era de la moderna cibernética, las civilizaciones se han preocupado de las delicadas materias protocolarias y ceremoniales. En todo tiempo y lugar se fue arbitrando un compendio de normas para armonizar la representación de los distintos estamentos sociales; de ahí que alguien apuntase -con notorio acierto-que la ciencia y el arte del protocolo constituyen una mezcla inseparable entre la tradición del pasado y la complejidad del presente, marcado éste por el mayor sentido práctico y utilitario que preside la vida.(Rodríguez Ennes, L., 2003: 35)

Por lo tanto, el valor presente del Protocolo debe trascender de las modas y usos de un tiempo determinado, para considerarlo como regla general de comportamiento correcto en cualquier circunstancia de la vida social, especialmente en aquellos actos de carácter público, del Estado y de las diversas instituciones de la vida civil

${ }^{3}$ Extraído del Proyecto de Investigación "Proposta para unha reforma do Dereito Civil de Galicia a partir da experiencia histórica" (PGIDIT02C5039902PR) financiado por la Xunta de Galicia 


\section{El protocolo como norma jurídica}

Bobbio (1995: 23) reflexiona sobre la naturaleza de la norma jurídica, a partir del viejo debate sobre la dificultad de que, al mismo tiempo, pueda ser justa, válida y eficaz. Sustentándose en las funciones fundamentales del lenguaje (la descriptiva, la expresiva, la pre formativa y la prescriptiva), concluye que, incluso, una orden puede ser simplemente manifestada como expresión de un deseo, de una voluntad. Y frente al imperativo del mandato obligatorio, cabe la formulación -con equivalente resultado de eficacia- de lo que denomina "consejos"; pero quien manda tiene autoridad para mandar, y quien aconseja no puede pretender siempre el derecho de poder de hacerlo. Los mandatos se imponen, los consejos, no. Una norma jurídica es un mandato.

Una norma jurídica es un enunciado jurídico dotado de estabilidad y destinado a una colectividad amplia. Además, toda norma jurídica tiene que estar justificada. Las normas de Protocolo, en cuanto que pertenezcan a la categoría de preceptos jurídicos, pudieran encuadrarse en lo que los tratadistas denominan leges imperfectae; esto es, que su infracción no solamente no produce la anulación -como en otros casos- del acto cometido, sino que tampoco se impone sanción alguna al infractor. En el ámbito de la función pública abundan este tipo de normas, pero su no cumplimiento, en la mayoría de los casos, no merece otro reproche que el de carácter moral. También se las llama "normas no sancionadas".

Ramos (2010: 25) sostiene que en no parece que, en principio haya nada que temer, salvo el reproche social, el bochorno o el deslucimiento, porque en la organización de un acto oficial se infrinja una norma de Protocolo. Más o menos algo parecido puede suceder en otros países, donde también es común observar incumplimientos de Protocolo en el ámbito de las autoridades académicas o civiles, aunque no así, en el de las militares, por principio.

El ordenamiento jurídico influye siempre, en función de su estructura, en La distribución del poder, de la precedencia de quien lo encarna, dice Weber:

El reconocimiento del poder, tanto político como económico es retribuido como un honor social. El orden jurídico puede garantizar tanto el poder como la existencia del honor [...] Llamamos "orden social" a la forma en que se distribuye el honor social dentro de una comunidad entre grupos típicos pertenecientes a la misma. (Weber, 1983: 45)

La cuestión clave que se nos plantea, pues, con respecto al asunto tratado, es el de la eficacia. Kelsen afirmaba que la eficacia del Derecho estribaba en el hecho de que los hombres deberían comportarse como las normas jurídicas establecían, para concluir que la eficacia no es pues una cualidad de las normas, sino una consecuencia de la acción de los hombres. Lo cual es cierto, pero no lo es menos que la eficacia habrá de medirse en cuanto que la norma sirva o no para alcanzar los fines que su contenido propone. Y ¿cuándo sería más eficaz una norma: cuando sus destinatarios la respetan por temor a una sanción o cuando la cumplen por convencimiento de que es buena para la sociedad?. López-Nieto y Mallo precisa:

$\mathrm{Al}$ referirme a las normas de protocolo, no intento aludir a su grado de obligatoriedad, distinguiendo entre normas jurídicas y usos sociales, sino que, en mi opinión, las normas de protocolo se identifican por el fin a que se dirige su mandato. [...] Toda norma que tienda a ordenar una conducta protocolaria será norma de esa naturaleza [...]. Las normas de protocolo obedecen todas, directa o indirectamente, a un mismo fundamento, esto es, la des- 
igualdad de los hombres. A diferencia de lo que suele acontecer con la generalidad de las normas jurídicas, las de protocolo se fundamentan esencialmente en tales desigualdades. ? (López-Nieto y Mallo, 2006: 45):

Las normas de Protocolo pueden dividirse en tres grandes grupos:

- Normas de carácter ético o derivadas de un deber moral: la buena educación y el respeto a los demás.

- Normas de naturaleza social (convenciones y usos sociales): determinado tipo de atuendo según el carácter del acto.

- Normas jurídicas: dictadas por la autoridad que puede hacerlo, por ejemplo, el Decreto Ley de Precedencias del Estado).

En la vida cotidiana, tanto en el pasado como en el presente, las normas morales son, en oposición a las normas jurídicas, considerando el asunto sociológicamente, normas de conducta condicionadas por la religión o por la convención; y sus límites, con respecto al derecho, son graduales. Las reglas convencionales representan normalmente la manera como se convierten en puras y efectivas regularidades de actuar, meras costumbres, por lo tanto, en normas obligatorias, garantizadas casi siempre por la coacción psíquica. Y el simple hecho de la repetición regular de fenómenos favorece que tales fenómenos adquieran la dignidad de algo normativamente ordenado, nos dice Weber (1983: 56)

\section{Protocolo y valor histórico}

Dejado sentado que el Protocolo, por sus variados perfiles, puede ser estudiado dentro del desarrollo de las Ciencias Jurídicas (o de la ética o de los comportamientos sociales, usos y costumbres), en cuanto que está formulado como una norma (aunque pueda ser imperfecta o sin sanción, aparte de su valor como uso social o tradición, uso costumbre, que son igualmente fuentes de Derecho en nuestro caso), hemos de adentrarnos en el estudio de su historia. Por no remontarnos más allá de un periodo relativamente reciente del devenir de España, tomamos como punto de partida el estudio del profesor de antropología de la Universidad de Oxford, Carmelo Lison Tolosana, quien en su discurso de ingreso en la Real Academia de Ciencias Morales y Políticas trató el tema "La imagen del Rey. "Subtitulado" Monarquía, Realeza y poder ritual en la casa de los Austrias". De modo especialmente expresivo escribe.

El quince de Agosto de 1548, a la hora del almuerzo y después de seis meses de ensayo y preparación, fue introducido en la Corte del Príncipe Felipe el estilo y uso de la Casa de Borgoña: el cambio no bien recibido por los castellanos ni por las Cortes había sido ordenado un año antes por el Emperador ${ }^{4}$. (Lison Tolosana, 1991: 17 y ss.)

${ }^{4}$ El mismo Emperador Carlos, pleno de poderes para otras cosas se tuvo que ceñir a los dictados de lo que estaba establecido, y así cuando se reunió la Dieta de Worms asistieron tantos príncipes, prelados, dignatarios que faltaron los víveres y el alojamiento y se perdieron dos meses discutiendo sobre los asientos de unos y otros y ante la imposibilidad de llegar a un acuerdo, las sesiones se celebraron de pie. También el mismísimo Emperador esperó en la puerta de la ciudad de Aquisgrán en el año 1520, varias horas hasta que se resolvió la disputa por la precedencia originada entre el Duque de Juliers y el Príncipe de Anhalt. 
Se abre con los Austrias un período interesantísimo para los estudiosos del protocolo, por ser una época en la que estaba todo reglamentado. Nada escapaba a la inflexible regla del protocolo, toda la vida de la corte estaba regida con precisión desde que se levanta el sol hasta el ocaso, desde que el portero abre la primera puerta hasta que la cierra. Es un periodo rico en anécdotas, riñas, disputas por precedencias entre los representantes del Rey de España y los de otros reinos, especialmente el de Francia, que tuvieron en muchas ocasiones término en luchas y peleas.

A lo largo de estos siglos hasta nuestros días, la investigación histórica viene a demostrar que el Protocolo y el Ceremonial formaban parte de las preocupaciones prioritarias del Poder, de modo que aparecen sucesivos documentos que perfilan hasta extremos increíbles la vida de la Corte y las relaciones entre la sociedad y el que la gobierna.

Ya en nuestro tiempo, tras la aprobación de la Constitución era imprescindible disponer de una norma que regulara al Protocolo de Estado, cosa que se hizo en 1983, con el Real Decreto 2099/83, de 4 de agosto, sobre Ordenación General de Precedencias del Estado, lo que provocó conflictos que llegaron al Tribunal Constitucional, puesto que Cataluña había aprobado su propio reglamento dos años antes, con previsiones que chocaban frontalmente con las disposiciones superiores del Estado, caso que se repite con el País Vasco. Todos los pleitos se resolvieron a favor del Estado, dado que los estatutos de autonomía no habían asumido competencias, en esta materia, y era estatal la titularidad ordenar el protocolo, si bien con el reconocimiento explícito de la facultad de las comunidades autónomas para regular sus propios órganos, cosa que no han hecho todas las autonomías.

\subsection{La estructura del Protocolo oficial en España}

El Reino de España cuenta con tres grandes servicios de Protocolo en la Administración General a los que se unen, naturalmente, los que poseen otros departamentos ministeriales y, en el seno de otras Administraciones, los de las Comunidades Autónomas y los de las entidades locales:

- El Servicio de Protocolo de la Casa de S. M. el Rey.

- El Servicio de Protocolo del Ministerio de Asuntos Exteriores, cuyo titular recibe tradicionalmente el título de Introductor de Embajadores.

- El Departamento de Protocolo de la Presidencia del Gobiernos, dependiente de la Secretaría General. Su titular tiene rango de Director General. El actual De-

5 Entre sus funciones principales se encuentran:

- En lo relativo al Protocolo de la Presidencia del Gobierno, la coordinación y dirección del protocolo de los viajes, visitas y otras actividades oficiales del Presidente del Gobierno y, en su caso, de los Vicepresidentes del mismo.

- Por lo que respecta al Protocolo del Estado, la coordinación, interpretación y ejecución de las normas protocolarias y la dirección de los actos relativos al régimen de Protocolo y Ceremonial del Estado, es decir, la coordinación y dirección, en su caso, del protocolo de los actos de carácter general realizados en España en los que concurran autoridades de distinto orden (nacionales, autonómicas y locales). Normativa en materia de precedencias oficiales. Hemos dicho que el Departamento es el encargado de aplicar e interpretar las normas existentes en materia de Protocolo, pero ¿cuáles son estas normas? 
partamento de Protocolo de la Presidencia del Gobierno es el heredero de las Jefaturas de Protocolo del Estado -creada por Real Decreto 2101/83, de 4 de agosto-y de la de la Presidencia del Gobierno -creada, por su parte, por Real Decreto 183/1987, de 30 de enero-. El posterior Real Decreto 838/1996, de 10 de mayo, consagró la creación del Departamento de Protocolo de la Presidencia del Gobierno que, a partir de dicho momento, asumiría las funciones de las citadas Jefaturas.

Partiendo del sistema de fuentes del Derecho consagrado en nuestro Ordenamiento Jurídico y centrándonos en primer lugar en la normativa legal, el punto de partida debe ser, necesariamente, nuestra norma superior -la Constitución Española de 27 de diciembre de 1978- que, pese a no contener sino escasas normas específicas en materia de Protocolo Oficial, determina y desarrolla la forma política del Estado (Monarquía parlamentaria), la división de poderes (legislativo, ejecutivo y judicial), las instituciones en que los mismos se articulan (Cortes, Gobierno y Tribunales) y su estructura territorial, consagrando la existencia de las Administraciones Autonómica (Comunidades Autónomas) y Local (Municipios, Provincias y, en su caso, Islas). Todo ello tiene una incidencia directa a la hora de comprender, analizar, interpretar y aplicar la normativa subsidiaria por la que se rige nuestro Protocolo Oficial.

En un segundo escalón encontramos la norma que, con rango de ley (Real Decreto), constituye aún hoy en día el principal referente a la hora de ordenar los actos oficiales, sean de carácter general o especial, en todo el territorio español. Se trata del Real Decreto 2099/83, de 4 de agosto, sobre Ordenación General de Precedencias en el Estado.

Por último, cabe hacer una mención a la especial importancia que en este ámbito reviste el derecho consuetudinario (las costumbres y tradiciones) e, incluso, los meros usos sociales, que tradicionalmente han venido colmando el vacío del legislador en la materia y que, en más de una ocasión, han inspirado la propia actividad legislativa y flexibilizado su aplicación. "Las costumbres o tradiciones del lugar", a las que el propio Real Decreto 2099/1983 hace referencia -incluso las extranjeras, en su caso, especialmente cuando atañen al terreno de la moral o de la historia- deben ser conocidas y respetadas, cuando proceda, si no deseamos herir determinadas sensibilidades

\subsection{La adecuación del protocolo a la realidad nacional}

Entre las conclusiones de las II Jornadas Internacionales de Comunicación Institucional a Imagen Pública, dentro del XIII Curso Complementario de Comunicación y Protocolo, celebrado en la Facultad de Ciencias Sociales y de la Comunicación de la Universidad de Vigo, los días 17 y 18 de abril de 2013, con asistencia de especialistas de toda España y Portugal, se estableció que es preciso dotar al país de una norma general de Protocolo, con rango de Ley que contemple la realidad actual del país. En este sentido, Juan Carlos Gafo (2010:39) que fue jefe de Protocolo de la Presidencia del Gobierno, señala que la normativa que existe hoy en nuestro país en materia de Protocolo es dispersa, incompleta y, en cierta medida, obsoleta.

Expertos y profesionales vienen reclamando sistemáticamente en los últimos años la reforma, actualización o sustitución del Real Decreto 2099/1983 -que en su día fue 
calificada como positiva, pues aportó lo que algunos han denominado "paz protocolaria"- por otra norma acorde con las nuevas realidades, tanto nacionales como internacionales con objeto de adaptarla al progresivo desarrollo de la España autonómica; a la desaparición o cambio de nombre de numerosos cargos y aparición de otros nuevos -cuya inserción en el ordenamiento de precedencias crea constantes conflictosdesde la fecha de su publicación; y a la revisión (o ausencia, en su caso) de alguno de los criterios que en ella se recogen.

Precisamente, desde el punto de vista del trabajo intelectual y la revisión de las vigentes normas legales sobre la materia, los estudios de Protocolo pueden y deben desarrollar líneas de investigación que ayuden a las autoridades públicas a formular criterios para dotar al país de una nueva Ley de Protocolo.

Entre esas tareas pendientes de desarrollar destacan:

a) Eliminar la dispersión de cargos y situaciones que han cambiado.

b) Revisar y clarificar criterios. Es decir, qué carácter tiene un determinado acto (general del Estado o especial de una comunidad o un ente). En materia de representaciones $^{6}$, la doctrina más extendida hoy, frente a la que consagra el Real Decreto, es la que considera que las representaciones deben ser reconocidas de pleno derecho cuando estén motivadas exclusivamente por enfermedad, vacante o ausencia oficial del titular y la representación haya sido legitimada por acuerdo plenario de la Corporación y publicada en documento público.

c) En el R.D. existen, por otra parte, toda una serie de cargos que han desaparecido, cambiado de nombre o han sido creados con posteridad. Solamente las comunidades de Andalucía, Cataluña, Comunidad Valenciana, Navarra, Murcia, La Rioja, Islas Baleares y Canarias disponen de normativa propia aprobada por sus respectivos gobiernos. La falta de estas normativas, junto al vacío del Decreto nacional a propósito de determinados cargos autonómicos provoca en las regiones numerosos conflictos protocolarios que obligan a decisiones singulares, en muchos casos, sin que haya unificación de criterios entre las propias autonomías.

La incorporación de España a la Unión Europea introduce también nuevos elementos que, obviamente, no pudo prever el Real Decreto de 1983: colocación de autoridades de la Unión Europea cuando concurren con autoridades españolas -aquí el criterio general que se aplica es que la autoridad comunitaria se situará a continuación de su homólogo español.

Sostiene $\mathrm{Gafo}^{7}$ (2010: 39) que el proceso democratizador de la sociedad española haya acrecentado notablemente la atención que se presta a las cuestiones protocolarias. La interacción entre estos actores, especialmente entre los públicos -los que for-

${ }^{6}$ Actualmente, sólo se admite la representación del Rey y del Presidente del Gobierno; es decir, cuando una persona representa al monarca o al presidente del ejecutivo recibe los mismos honores y tratamiento que el cargo a quien representa. Pero no en los otros casos.

${ }^{7}$ La multiplicación de interlocutores ha venido acompañada del muy significativo aumento en la densidad de los contactos, actividades, viajes y todo tipo de reuniones y encuentros bajo una multiplicidad de formatos, con una fuerte tendencia hacia la "multilateralización". Cada vez son más numerosas las que podríamos calificar de "operaciones especiales": Cumbres 
man parte del conocido como Protocolo oficial- y los no oficiales es creciente y enriquecedora para ambos. Mundos como el del deporte, la empresa, o las ONG's, tienen cada vez mayor presencia e interacción con el Protocolo oficial.

\subsection{EI Protocolo como materia de estudio}

¿Estamos pues ante una materia que nos ofrezca elementos suficientes para la investigación científica? Giddens (2002: 30) sostiene que muchos aspectos de la vida social que, aparentemente, sólo interesan a un individuo, son en realidad, cuestiones generales. La Sociología, o mejor el estudio sociológico de una materia, nos permite ver el mundo, a través del propio asunto, desde diversos puntos de vista. La sociología nace de la mano de los grandes cambios sociales y políticos que se producen en el mundo a partir del siglo XVIII. Una de las preguntas a las que trataron de dar respuesta los primeros sociólogos era cómo era la naturaleza humana y cómo se conformaba la estructura de la sociedad.

Es de destacar que, aun antes de la actual crisis, las grandes corporaciones mercantiles, de diverso tipo, empresas, corporaciones y bancos, incrementaron sus inversiones y tecnología y en comunicación institucional y relaciones públicas, especialmente patrocinio y mecenazgo, en tanto reducían el gasto en publicidad simbólica. El puesto de jefe de Protocolo o responsable de este sector aparece diferenciado, con misiones y responsabilidad propias dentro del esquema general del Departamento de Comunicación, cuyo director ha ascendido desde el primitivo nivel de jefe de prensa al staff.

El protocolo actual dista mucho de la vieja definición de jerarquía o de poder (Fuente, 2010: 519). La misma definición del Presidente de la Generalidad de Cataluña, Jordi Pujol, que tanto gusta de repetir a los profesionales, "el Protocolo es la expresión plástica del Poder", no es ya una definición acertada en estos tiempos, según el director de Protocolo de los Premios Príncipe de Asturias, y reconocido pionero en este campo, actualmente al frente del ISPE (Instituto Superior de Protocolo y Eventos) y de los cursos de Protocolo de la Universidad Camilo José Cela.

Sostiene Carlos Fuente que en tiempos de globalización, que afectan también a la cultura y al Protocolo que requieren creación e imaginación:

El responsable de protocolo debe ser un gran creador de actos, un profesional imaginativo capaz de innovar. El protocolo actual demanda diseño imaginativo, más juventud intelectual, más tiempo para pensar, más discusión en equipo y menos actuación en solitario. [...] Un acto que no transmite sus fines es un mal acto. Por ello, hay que incluir necesariamente técnicas de comunicación y valorar el interés periodístico. Hay que diseñar los actos con criterios periodísticos, máxime si queremos llegar a toda la sociedad, pero eso sin perder la identidad propia del acto o de la institución anfitriona, su cultura o tradiciones. (Fuente, 2010: 519)

(iberoamericanas, OTAN, Consejos de la UE, etc.), Conferencias (de Paz, como la de Oriente Medio), grandes eventos internacionales (de carácter deportivo, Exposiciones Universales, etc.). Todas ellas exigen para su organización protocolaria un importante esfuerzo multidisciplinar, intervención de equipos interministeriales y una estructura de coordinación que se revela esencial para el éxito de las mismas. 
Las nuevas tecnologías obligan a un ejercicio constante de actualización, de revisión de formatos y de introducción de nuevos lenguajes. Coincidimos con Fuente en que el protocolo se ha extendido al conjunto del tejido social, y que ha dejado de ser un coto propio de lo oficial. El Protocolo está presente en todo y como tal hay que darle una respuesta, según las circunstancias del entorno.

Es pues en este terreno, considerando que el Protocolo se instala dentro de los objetivos de comunicación de las entidades, las empresas y las instituciones, donde, a nuestro entender, se abre un campo inmenso de posibilidades para convertirlo en una disciplina plenamente científica, con elementos propios, que permita formular una teoría diferenciada y que lo eleve del rango de técnica auxiliar al servicio de la imagen de las instituciones.

Con todos estos antecedentes, será posible construir una verdadera Ciencia del Protocolo en la medida que se sigan los parámetros fundamentales para construir un genuino saber científico. Partir de hechos ciertos, investigarlos y obtener conclusiones. Analizar y desmenuzar esos hechos, estableciendo relaciones entre ellos, tratar de descomponerlos, de entender sus componentes; intenta descubrir los elementos que componen cada totalidad, y las interconexiones que explican su integración. Los resultados han de ser expuestos con claridad y deberán ser verificados. Para ello se deberá partir de un trabajo metódico y planificado. Ha de construirse una ciencia sistemática, no un manojo de informaciones inconexas. Ha de ser capaz de ubicar los hechos singulares en pautas generales, y los enunciados particulares en esquemas amplios.

Una verdadera Ciencia intenta explicar los hechos en términos de leyes, y las leyes en términos de principios. Procura responder al porqué ocurren los hechos, cómo ocurren y por qué no ocurren de otra manera. Es predictiva porque trasciende la masa de los hechos de la experiencia, imaginando cómo puede haber sido el pasado y cómo podrá ser el futuro. La Ciencia es valiosa como herramienta remodelar la sociedad. A ella debe servir siempre, sea la ciencia que sea.

\section{Conclusiones}

El enfoque científico para la crear una Ciencia del Protocolo es un proceso sistemático, disciplinado y controlado. Se basa en observaciones empíricas, arraigadas en la realidad objetiva.

El enfoque científico de partida debe ser general e intenta establecer explicaciones conceptuales o teorías referentes a las relaciones entre fenómenos sociales en los que intervienen el Protocolo, el Ceremonial y la Etiqueta.

La investigación científica sobre el Protocolo puede concretarse en términos de la utilidad práctica directa que se le supone. La investigación básica se dedica a ampliar la base de conocimientos en una disciplina en aras del conocimiento mismo. La investigación aplicada se enfocará en describir soluciones para problemas prácticos inmediatos y formular teorías exportables.

La construcción de una Ciencia del Protocolo debe partir de la delimitación de su ámbito de estudio sin pretender abarcar o extenderse de otros ámbitos de los que ya se ocupan otras familias de conocimiento dentro de las Ciencias de la Comunicación. En este sentido, es preciso reorientar las propias definiciones de la carrera matriz y re- 
componer las salidas profesionales hacia las que se orienta la utilidad práctica de su conocimiento.

La Ciencia del Protocolo no puede construirse aisladamente de la Historia, la Sociología o la Política como apoyos fundamentales. Es por tanto, una Ciencia de síntesis al servicio de la excelencia en la presentación de los actos humanos en el espacio de lo institucional, la empresa, las corporaciones y las entidades públicas.

\section{Referencias}

BERISSO, María (2008): Protocolo y Ceremonial. Buenos Aires, Espasa.

BOBBIO, Norberto (1995): Teoría general del Derecho. Madrid, Debate.

BRUNER, Jerome Seymour (1965): The process of education. Cambridge, MA, Cambridge University Press.

CARRERAS PANCHÓN, Antonio et al (1994): Guia práctica para la elaboración de un trabajo científico. Bilbao, CITA. Publicaciones y Documentación.

DE URQUIZA, Adolfo J. (1932): Ceremonial público. Madrid, Edición propia.

ECO, Umberto (1983): Cómo se hace una tesis. Barcelona, Gedisa.

FUENTE, Carlos (2010): "Cincuenta medidas reformadoras para modernizar el protocolo clásico" en Estudios de Comunicación y Protocolo (I). Vigo, Cursos Complementarios. Universidad de Vigo, pp. 519-544.

GAMBARA, Hilda (1995): Diseño de investigaciones. Cuaderno de práctica. Madrid, McGrawHill.

GIDDENS, Anthony (2002): Sociología. Madrid, Alianza Editorial.

GAFO, Juan Carlos (2010): "La estructura actual de la Administración de Protocolo en España", en Estudios de Comunicación y Protocolo (I). Vigo, Cursos Complementarios. Universidad de Vigo, pp. 39-52.

LISÓN TOLOSANA, Carmelo (1991): La imagen del Rey. Monarquía, realeza y poder ritual en la Casa de los Austrias. Madrid, Espasa-Calpe.

LEÓN, Orfelio G. y MONTERO, Ignacio (1997): Diseño de investigaciones. (2 ${ }^{\mathrm{a}}$ Edición). Madrid, McGrawHill.

LÓPEZ-NIETO y MALLO, Francisco (2006): Manual de Protocolo. Barcelona, Ariel

OTERO ALVARADO, María Teresa (2000): Teoría y estructura del Ceremonial y el Protocolo. Sevilla, Megablum.

RAMOS, Fernando (2010): "Carácter y eficacia de las normas de Protocolo", en Estudios de Comunicación y Protocolo (I). Vigo, Cursos Complementarios. Universidad de Vigo, pp. 25-38.

RODRÍGUEZ ENNES, Luis (2003): “Apuntes históricos en torno a la evolución del Protocolo desde la Roma Imperial hasta el final del Antiguo Régimen", en RAMOS, Fernando (editor): Curso Superior de Comunicación y Protocolo. Vigo, Extensión Universitaria, Universidad de Vigo. 
SARRES, Jean (1982): Manuel practique de Protocole. Paris, Editions de la BIevre. SGRELLI, Massimo (2006): Il Ceremoniale. El Ceremoniale moderno e il Protocolo di Stato. Regolee scritte e non scritte. Roma, Master Edizioni.

URBINA, José Antonio (2000): El protocolo en los negocios. Madrid, Temas de hoy. VILARRUBIAS, Felio A. (2000): Tratado de Protocolo de Estado e Internacional, Oviedo, Nobel.

WEBER, Max (Edición en español 1993): Economía y Sociedad. Madrid, Fondo de Cultura Económica. 